\title{
Iatrogenic root fracture secondary to extraction of impacted mandibular third molar that is masked by severe inflammation in the maxillofacial region - a case report
}

\author{
Stanimir Kisselov ${ }^{1}$, Tasho Gavrailov ${ }^{1}$, Petia Pechalova ${ }^{1 *}$ and Desislava Konstantinova ${ }^{2}$ \\ ${ }^{1}$ Department of Oral Surgery, Faculty of Dental Medicine, Medical University, Plovdiv, Bulgaria \\ ${ }^{2}$ Department of Prosthetic Dentistry, Faculty of Dental Medicine, Medical University, Varna, Bulgaria
}

\begin{abstract}
The extraction of impacted and semi-impacted third molars is a common oral surgical procedure. The authors present a case of iatrogenic complication treated by root amputation - root fracture of the distal root of the adjacent second molar that is diagnosed few months following the extraction of impacted mandibular third molar. The follow-up examination after one year reveals complete healing of the bone in the extraction wound, as well as in the site of root amputation. The author's emphasis on the importance of preoperative planning for avoiding such complications.
\end{abstract}

\section{Introduction}

The extraction of impacted and semi-impacted third molars on the mandible and maxilla is a common surgical procedure that is often deemed routine but is associated with increased risk of complications. Possible postoperative complications can be minor (transitory or permanent) and major (transitory) [1]. The abscesses and fascial space infections of maxillofacial region are acute inflammations influenced by local and systemic factors which are caused by mixed microflora, consisting of aerobes and anaerobes in $94-96 \%$ of the cases [2]. Their usual manifestation is loss of facial symmetry, purulent exudation, pain, impaired function and decline of systemic health.

\section{Case report}

29 years old female patient searched for help at her dentist due to failure of eruption of impacted tooth 38 (Figure 1). The patient complains of increasing swelling and pain in the surgical site following the extraction. Clinical evidence of inflammation in left sulcus mandibulo-lingualis, pterygomandibular and submasseteric regions is present. The left submandibular region is affected later and the incipient abscess of the floor of the mouth calls for hospitalization of the patient, at which point surgical incisions and drainage complemented with pharmacological medication is provided.

Two months later the patient complains of pain and incipient swelling at the site of the extraction. Radiography reveals empty socket of the third molar and transverse fracture of the distal root of tooth 37 at cervical level (Figure 2). We decided on conservative-surgical treatment plan (root amputation) that included endodontic treatment of tooth 37 (Figure 3) and removal of its distal root, as well as revision of the extraction site of 38 . Immediate postoperative result is presented in figure 4. Additional medication with $600 \mathrm{mg}$ Clindamycin three times a day for the next 8 days is assigned. Follow-up examination after one year reveals clinical and radiological proof of successful healing, no periapical changes in tooth 37 and no further complains (Figure 5).

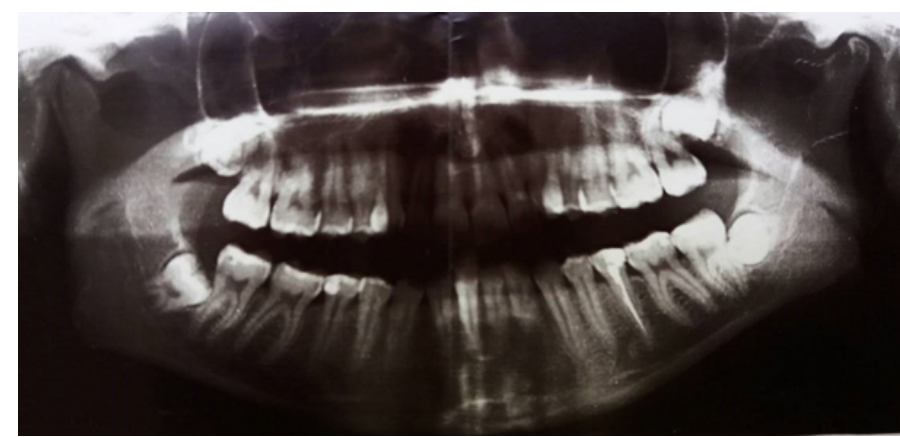

Figure 1. Prior to removal of left impacted mandibular third molar

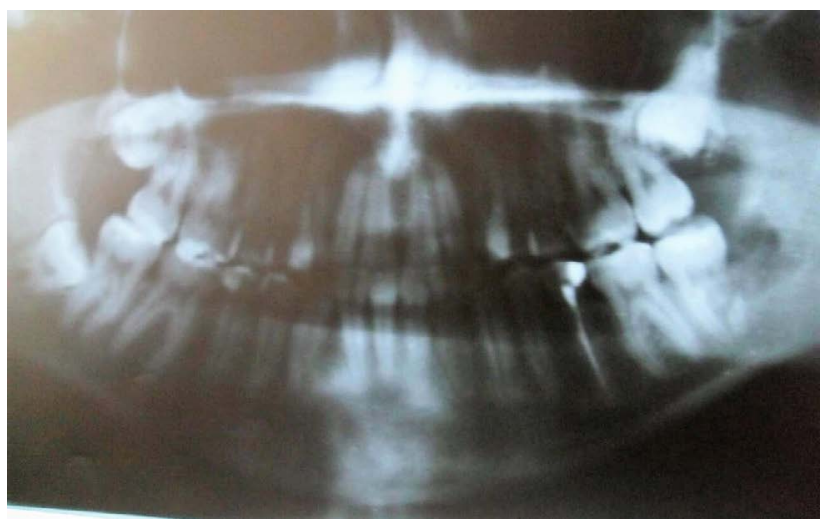

Figure 2. Fracture to the distal root of second mandibular left molar due to surgical removal of left impacted mandibular third molar.

*Correspondence to: Petia Pechalova, PhD, MD, DDS, "Hristo Botev" 3 Blv, Plovdiv, Bulgaria, E-mail: pechalova@abv.bg

Key words: impacted molar, root fracture, complications, root amputation

Received: February 27, 2018; Accepted: March 22, 2018; Published: March 26, 2018 


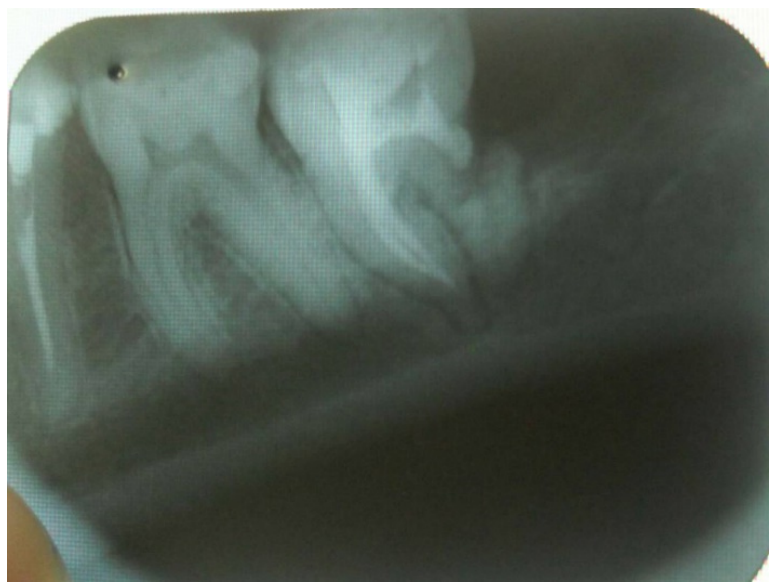

Figure 3. Endodontic treatment of second mandibular left molar was provided before the surgery.

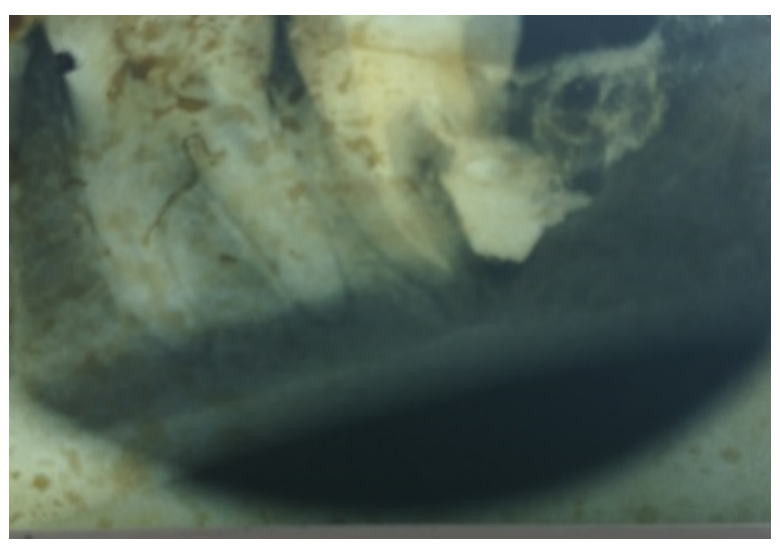

Figure 4. Immediate postoperative radiograph.

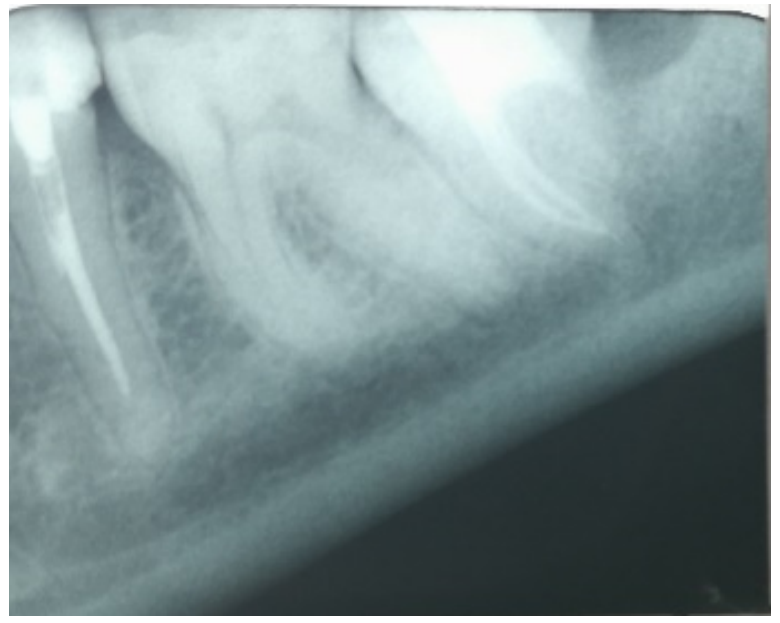

Figure 5. Postoperative result one year following surgery

\section{Discussion}

Though considered relatively routine procedure by the experienced clinician the surgical extraction of mandibular third molar may sometimes be accompanied by various, potentially lethal complication that can occur during, immediately after or sometime after the procedure.

According to Jerje et al. there is a clear relation between the experience of the surgeon and the frequency of postoperative complications after removal of third molar. This observation is valid for the cases of trismus, oropharyngeal inflammation, delayed healing, infection, dry socket and paresthesia. In contrast, postoperative bleeding is more frequently observed in patients that were treated by more experienced surgeons. Supposedly, more experienced surgeons are better able to identify potential complications in advance and plan for appropriate treatment [3].

Boulox et al. present the rest of the factors that influence the occurrence of postoperative complications after mandibular third molar extraction - age, sex, comorbidities, oral contraception, pericoronitis, poor oral hygiene, smoking, level of impaction, relation to inferior alveolar nerve, duration of the procedure, surgical technique, preoperative antibiotics, local antisepsis, anesthesia and local medication of the socket [4].

The most often postoperative complications following surgical removal of third molar include pain, bleeding, soft tissue trauma, trismus, swelling, infection, dry socket, delayed healing, nerve damage to the lingual, inferior alveolar and sometimes the mylohyoid nerve [5]. Occasionally, dislocation of tooth or tooth fragment in neighboring anatomical space, perforation of maxillary sinus, damage to adjacent teeth and structures, damage to TMJ, jaw fracture, aspiration or swallowing of teeth are described [6].

Renton et al. establish that the risk of complications associated with use of extreme force during extraction of impacted mandibular molar increases with age [7]. The study of Osborn et al. reveals that the risk of complications relative to impacted mandibular molar's extraction is the greatest [8]. Such findings support the experience of our patient, who was 29 years old.

These evidences solidify our belief, that the extraction of mandibular molars is a hazardous procedure associated with high level of complexity. Therefore, we consider the paramount importance of preoperative planning for the overall success of the surgical treatment. The clinician should pay attention at the patient's age, sex, medical history, as well as at the radiological information regarding third molar's position. Proper armamentarium and operation technique should be utilized and there should be awareness about the potential complications. It is important to remember that patient's treatment begins preoperatively and lasts until his/her full recovery.

Non-diagnosed iatrogenic fracture to the distal root of the second molar following surgical removal of the third molar premised the severe odontogenic infection which later caused hospitalization of our patient. Unfortunately, the fracture remained undiscovered during her stay in the clinic and two months later the incipient inflammation symptoms prompted us to examine the region thoroughly. Only then was the underlying cause for the complications successfully identified.

Chiapasco et al. evaluate the incidence of trauma to adjacent teeth during surgical extraction of third molar at $0.3-0.4 \%$ [9]. Such complications may include fracture of adjacent tooth's root, crown, restoration, as well as its luxation or expulsion [10]. Weirong Tang et $a l$. further postulate that restorations to three and more crown aspects significantly increase the risk of fracture. The authors emphasize on the relatively frequent occurrence of subgingival fractures to teeth that received endodontic treatment [11].

Neeraj Malhotra et al. summarize that the cause for root fracture is usually kinetic trauma [12]. They propose permanent fixation of the root fragment to the proximal aspects of adjacent teeth in patient 
Kisselov S (2018) Iatrogenic root fracture secondary to extraction of impacted mandibular third molar that is masked by severe inflammation in the maxillofacial region - a case report

with good oral hygiene. Another option is reflection of flap and direct fixation of the fragment to the intact root surface.

Single-rooted teeth with complete infracrestal root fractures combined with non-vital pulp, bone resorption or periodontal disease are to be removed. Multi-rooted teeth with fracture to one of the roots or the furcation region are indicated for root amputation, hemisection or extraction. The amputation or resection of roots may be the only option for conservation of the remaining structure of the tooth and should be considered as valid alternative to radical surgical extraction of the entire tooth. Bony cover of the remaining root greater than $50 \%$ of its surface is important prerequisite for successful root resection.

\section{Conclusion}

Surgical extraction of impacted third molar is associated with certain risk of complications that may occur regardless of surgeon's expertise. However, optimal preoperative planning and diagnostics are paramount to clinical success. The difficulty of the procedure, often determined by the position of the molar relative to other adjacent structures, should be assessed by the dentist in light of his own abilities and experience and the patient can be referred to expert oral or maxillofacial surgeon.

\section{References}

1. Chuang SK, Perrott DH, Susarla SM, Dodson TB (2008) Risk Factors for Inflammatory Complications Following Third Molar Surgery in Adults. J Oral Maxillofac Surg 66: 2213-2218. [Crossref]
2. Renton T (2010) Summary of: Experience in third molar surgery: An update. Br Dent J 209: 36-37. [Crossref]

3. Bouloux GF, Steed MB, Perciaccante VJ (2007) Complications of Third Molar Surgery. Oral Maxillofac Surg Clin North Am 19: 117-128.

4. Bui CH, Seldin EB, Dodson TB (2003) Types, Frequencies, and Risk Factors for Complications after Third Molar Extraction. J Oral Maxillofac Surg 61: 1379-1389. [Crossref]

5. Park SY, Shin SY, Yang SM, Kye SB (2009) Factors Influencing the Outcome of RootResection Therapy in Molars: A 10-Year Retrospective Study. J Periodontol 80: 32-40. [Crossref]

6. Renton T, Smeeton N, McGurk M (2001) Factors predictive of difficulty of mandibular third molar surgery. Br Dent J 190: 607-610. [Crossref]

7. Osborn TP, Frederickson G, Small IA, Torgerson TS (1985) A prospective study of complications related to mandibular third molar surgery. J Oral Maxillofac Surg 43: 767-769. [Crossref]

8. Chiapasco M, De Cicco L, Marrone G (1993) Side effects and complications associated with third molar surgery. Oral Surg Oral Med Oral Pathol 76: 412-420. [Crossref]

9. Marciani RD (2012) Complications of Third Molar Surgery and Their Management Atlas Oral Maxillofac Surg Clin North Am 20: 233-251. [Crossref]

10. Tang W, Wu Y, Smales RJ (2010) Identifying and Reducing Risks for Potentia Fractures in Endodontically Treated Teeth. $J$ Endod 36: 609-617. [Crossref]

11. Malhotra N, Kundabala M, Acharaya S (2011) A review of root fractures: diagnosis, treatment and prognosis. Dent Update 38: 615-628. [Crossref]

12. Guimarães E, Camila V (2011) Incidência dos acidentes e complicações em cirurgias de terceiros molares. Rev Odontol UNESP 40: 290-295.

Copyright: $(02018$ Kisselov S. This is an open-access article distributed under the terms of the Creative Commons Attribution License, which permits unrestricted use, distribution, and reproduction in any medium, provided the original author and source are credited. 